\title{
Diversification of rhacophorid frogs provides evidence for accelerated faunal exchange between India and Eurasia during the Oligocene
}

\author{
Jia-Tang Li ${ }^{\mathrm{a}, \mathrm{b}, 1}$, Yang Li ${ }^{\mathrm{b}, \mathrm{c}}$, Sebastian Klaus ${ }^{\mathrm{d}}$, Ding-Qi Rao ${ }^{\mathrm{a}}$, David M. Hillis ${ }^{\mathrm{e}, 1}$, and Ya-Ping Zhang ${ }^{\mathrm{a}, \mathrm{f}, 1}$ \\ ${ }^{a}$ State Key Laboratory of Genetic Resources and Evolution, Kunming Institute of Zoology, Chinese Academy of Sciences, Kunming 650223 , China; ${ }^{b} \mathrm{Chengdu}$ \\ Institute of Biology, Chinese Academy of Sciences, Chengdu 610041, China; ${ }^{\mathrm{d}}$ Department of Ecology and Evolution, Goethe University, 60438 Frankfurt am \\ Main, Germany; 'Section of Integrative Biology and Center for Computational Biology and Bioinformatics, University of Texas at Austin, Austin, TX 78712; \\ ${ }^{\mathrm{f} L a b o r a t o r y}$ for Conservation and Utilization of Bioresources, Yunnan University, Kunming 650091, China; and ${ }^{\mathrm{C}} \mathrm{College}$ of Life Sciences, Sichuan University, \\ Chengdu 610064, China
}

Contributed by David M. Hillis, January 15, 2013 (sent for review November 19, 2012)

The accretion of the Indian subcontinent to Eurasia triggered a massive faunal and floral exchange, with Gondwanan taxa entering into Asia and vice versa. The traditional view on the Indian-Asian collision assumes contact of the continental plates during the Early Eocene. Many biogeographic studies rely on this assumption. However, the exact mode and timing of this geological event is still under debate. Here we address, based on an extensive phylogenetic analysis of rhacophorid tree frogs, if there was already a Paleogene biogeographic link between Southeast Asia and India; in which direction faunal exchange occurred between India and Eurasia within the Rhacophoridae; and if the timing of the faunal exchange correlates with one of the recently suggested geological models. Rhacophorid tree frogs showed an early dispersal from India to Asia between 46 and $57 \mathrm{Ma}$, as reconstructed from the fossil record. During the Middle Eocene, however, faunal exchange ceased, followed by increase of rhacophorid dispersal events between Asia and the Indian subcontinent during the Oligocene that continued until the Middle Miocene. This corroborates recent geological models that argue for a much later final collision between the continental plates. We predict that the Oligocene faunal exchange between the Indian subcontinent and Asia, as shown here for rhacophorid frogs, also applies for other nonvolant organisms with an IndianAsian distribution, and suggest that previous studies that deal with this faunal interchange should be carefully reinvestigated.

phylogeography | molecular dating | tectonics

$T^{1}$ he tectonic collision between India and Asia induced a major biotic exchange from the former Gondwana continent to tropical Asia during the Early Cenozoic (1). Recent molecular studies have confirmed that Late Cretaceous faunal and floral elements entered Asia from Africa and Madagascar via the northward drifting Indian subcontinent (2-8). Thus, this tectonic event can be considered a major driver of biotic diversification, comparable to the "Great American Interchange" between North and South America after the closure of the Isthmus of Panama (9). However, the timing of the Indian-Asian collision and, of equal importance, the position of the Indian plate on its move northwards relative to the adjacent continents, is still under debate (10-17). A set of recent hypotheses is given in Table 1. Early studies suggested that the India-Asia collision occurred during the Paleocene or Early Eocene at 66-56 Ma (18), and many biogeographic studies relied on this date $(1,3,4)$. More recent geological and tectonic plate modeling analyses suggest that the final collision occurred much later, either around $35 \mathrm{Ma}(10,12)$ or between 25 and $20 \mathrm{Ma}$ (16), and was just predated by the collision of either Greater India with an intraoceanic volcanic island arc $(10,12)$ or the collision of a Tibetan-Himalayan microcontinent with Asia around $52 \mathrm{Ma}$ (16). Here we ask if these revised geological dates are in accordance with biogeographic data for a group of amphibians that occurs throughout this area and is restricted by the marine environment.

Tectonic collisions do not necessarily produce terrestrial connections. Thus, biogeographic research is needed to understand the biological implications of plate movements and collisions (19). In the case of northward drifting India, this applies especially for potential connections between India and Southeast Asia, as recently suggested, based on freshwater crab biogeography (19). Amphibians are ideal organisms to infer geological and environmental history due to their poor marine dispersal capabilities (3, 20-24). Frogs of the family Rhacophoridae (Old World tree frogs or shrub frogs) are a particularly appropriate animal group to test the timing of the Indian-Asian collision as their range comprises both India and East/Southeast Asia (21, 25) (Fig. S1 and Table S1). Previous studies identified the Madagascan Mantellidae as the sister group of the Rhacophoridae and concluded that the latter reached Eurasia via the northward drifting Indian subcontinent $(3,21,26,27)$, whereas three rhacophorid species that currently inhabit tropical Africa were shown to be the result of more recent dispersal from Asia $(28,29)$.

Here, we integrate phylogenetic, biogeographic, and molecular dating methods to reconstruct the comprehensive molecular phylogeny of rhacophorid frogs. In this time-calibrated phylogenetic framework, we reconstruct ancestral geographical areas to test $(i)$ if there was already a Paleogene biogeographic link between Southeast Asia and India; (ii) in which direction faunal exchange occurred between India and Eurasia within the Rhacophoridae; and (iii) if the timing of the faunal exchange correlates with one of the recently suggested geological hypotheses (Table 1), thus providing evidence for the paleoposition of the Indian subcontinent as it moved northward.

\section{Results}

Sequence Characteristics. The aligned mtDNA gene fragments consisted of 2,041 sites (excluding positions of unstable alignment). The mitochondrial data correspond to sites 726-2,666 of the Polypedates megacephalus mitochondrial genome (AY458598). Transitions and transversions within the five nDNA partitions accumulated in a linear way and gave no indication of saturation. The concatenated nuclear dataset comprised 3225 base pairs (bp), consisting of five Author contributions: J.-T.L. and Y.-P.Z. designed research; J.-T.L., S.K., D.-Q.R., D.M.H.,
and Y.-P.Z. performed research; J.-T.L. and Y.L. analyzed data; and J.-T.L., Y.L., S.K., D.M.H.,
and Y.-P.Z. wrote the paper.
The authors declare no conflict of interest.
Data deposition: The sequences reported in this paper have been deposited in the
Genbank database. For a list of accession numbers, see Table S1.
${ }^{1}$ To whom correspondence may be addressed. E-mail: lijt@cib.ac.cn, dhillis@mail.utexas.
edu, or zhangyp@mail.kiz.ac.cn.
This article contains supporting information online at www.pnas.org/lookup/suppl/doi:10. 1073/pnas.1300881110/-/DCSupplemental. 
Table 1. Geological hypotheses for the collision between the Indian subcontinent and Asia in regard to timing and sequence of events

Hypothesis

Plate positions

Time period

$\operatorname{Ref}(\mathrm{s})$.

Traditional view

One direct collision process between India and Eurasia

Early to Middle Eocene

42

Ali and Aitchison's hypothesis Acton's India model

India collides with an intraoceanic island arc, allowing (50 Ma)

for terrestrial connections; NE corner of the Indian

Early Eocene ( $55 \mathrm{Ma}$ )

10,12

subcontinent making a glancing contact with Sumatra, and subsequently with Burma

NE India is in contact with western SE Asia and might have been subaerially exposed

Continent-continent collision

Schettino and Scotese's India model

Van Hinsbergen's hypothesis
No connection; India $\sim 1,000 \mathrm{~km}$ further to the west of SE Asia
No connection; NE India submerged

Continent-continent collision
Collision of a Tibetan-Himalayan microcontinent/terrane with Asia
Subduction of the largely oceanic Greater India Basin along a subduction zone at the location of the Greater Himalaya
Final Indian-Asian collision

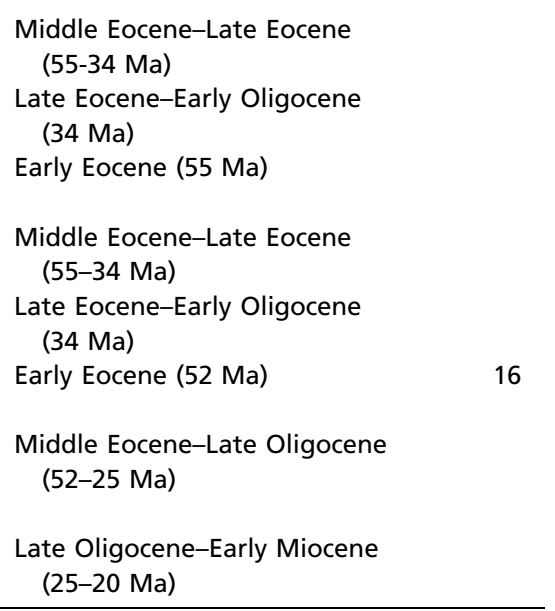

gene fragments: brain-derived neurotrophic factor (BDNF) (614 bp), proopiomelanocortin (POMC) (601 bp), recombination activating gene 1 (RAG-1) (1164 bp), rhodopsin exon 1 (RHOD) (315 bp), and tyrosinase exon 1 (TYR) (531 bp).

Phylogenetic Inference Identifies Rhacophorid Dispersal Between India and Southeast Asia. The phylogeny based on the combined mitochondrial and nuclear data are largely consistent with the results of the nuclear data alone (Fig. 1 and Figs. S2 and S3); only the position of the genus Chiromantis differs in the two analyses (neither topology with strong support). Also the estimated divergence times for our combined dataset and the nuclear data were largely consistent (Fig. 1 and Figs. S2 and S3).

Our combined phylogeny confirms the sister-group relationship of Rhacophoridae and Madagascan Mantellidae that separated around $59 \mathrm{Ma}$ (53-68 Ma highest posterior density (HPD), i.e., 95\% HPD interval; see node 1 in Fig. 1). The dichotomy between the East Asian Buergeriinae (only including Buergeria) and Rhacophorinae (comprising the remaining rhacophorids) is strongly supported and likely occurred during the Early Eocene around 50 Ma (46-57 Ma, 95\% HPD; node 2 in Fig. 1).

Within the subfamily Rhacophorinae the genus Liuixalus (Southeast-East Asia) is recovered as the sister group of the other rhacophorines, separating around $44 \mathrm{Ma}$ (39-50 Ma, 95\% HPD; node 3 in Fig. 1). The genera Theloderma and Nyctixalus (East Asia-Insular Southeast Asia) form a clade that also diverged early (36-47 Ma, 95\% HPD; node 4 in Fig. 1). Within the remaining Racophorinae that share a common ancestor around $40 \mathrm{Ma}$ (35-46 Ma, 95\% HPD; node 5 in Fig. 1), several clades with robust support can be identified: a clade of Kurixalus, Raorcheste, and Pseudophilautus ("group 2," time to the most recent common ancestor (tMRCA) 31-42 Ma, 95\% HPD; node 8 in Fig. 1); the genus Chiromantis (diverging at 33-43 Ma, 95\% HPD; node 7 in Fig. 1), comprising African representatives that separated between 19 and 28 Ma from their Asian relatives; and a clade consisting of the genera Polypedates, Taruga, Ghatixalus, and Feihyla ("group 1," tMRCA 30-39 Ma, 95\% HPD; node 10 in Fig. 1) that is sister to the genus Rhacophorus (tMRCA 31-41 Ma, 95\% HPD; node 9 in Fig. 1).

The results of the biogeographic inference (Fig. 2 and Table S2) indicated that the most recent common ancestor (MRCA) of the extant Rhacophoridae inhabited East/Southeast Asia. The earliest splits within Rhacophoridae most likely occurred in East Asia, resulting in the genera Buergeria and Liuixalus (Fig. 1), which currently inhabit South China and the islands of Taiwan, Hainan, and Japan. Hypothesis testing in the program Lagrange indicated that dispersal between India and Asia started after $35 \mathrm{Ma}$ but before 25 Ma (Table S3). We could identify several dispersal events from East/Southeast Asia and Insular Southeast Asia to the Indian subcontinent (Figs. 1 and 2 and Table S2): Four events from Insular Southeast Asia at 28-38 Ma, 23-32 Ma, 15-22 Ma, and 14-23 Ma (three events within "group 1" and Rhacophorus malabaricus); and two events from East/Southeast Asia (estimated between 13 and $30 \mathrm{Ma}$ ). However, more frequent dispersal events occurred from East/Southeast Asia to Insular Southeast Asia (five events between 6 and $50 \mathrm{Ma}$ ), and from Insular Southeast Asia to East/Southeast Asia (five events between 7 and $37 \mathrm{Ma}$ ). Within the genus Polypedates rhacophorids dispersed from India to Insular Southeast Asia between 10 and $28 \mathrm{Ma}$.

\section{Discussion}

Origin of Rhacophoridae. Our phylogenetic analyses support the sister relationship of Rhacophoridae and Mantellidae and is consistent with previous studies inferring the interrelationships of these two families with Ranixalidae and Dicroglossidae (3, 26, 27). As the Mantellidae currently occur only on Madagascar and Mayotte Island, and Ranoidea as a whole supposedly evolved in Africa (3), it has been suggested that Rhacophoridae and Mantellidae have a Gondwanan origin, and the northward drifting Indian plate mediated the dispersal of rhacophorids to Asia (3). This dispersal pathway is generally proposed for Late Cretaceous Gondwanan fauna and flora (2-8), including several other groups of anurans $(3,7)$. However, there is evidence for a post-Cretaceous biogeographic connection between Madagascar and India and/or the Seychelles (30-32). This dispersal path could also apply 

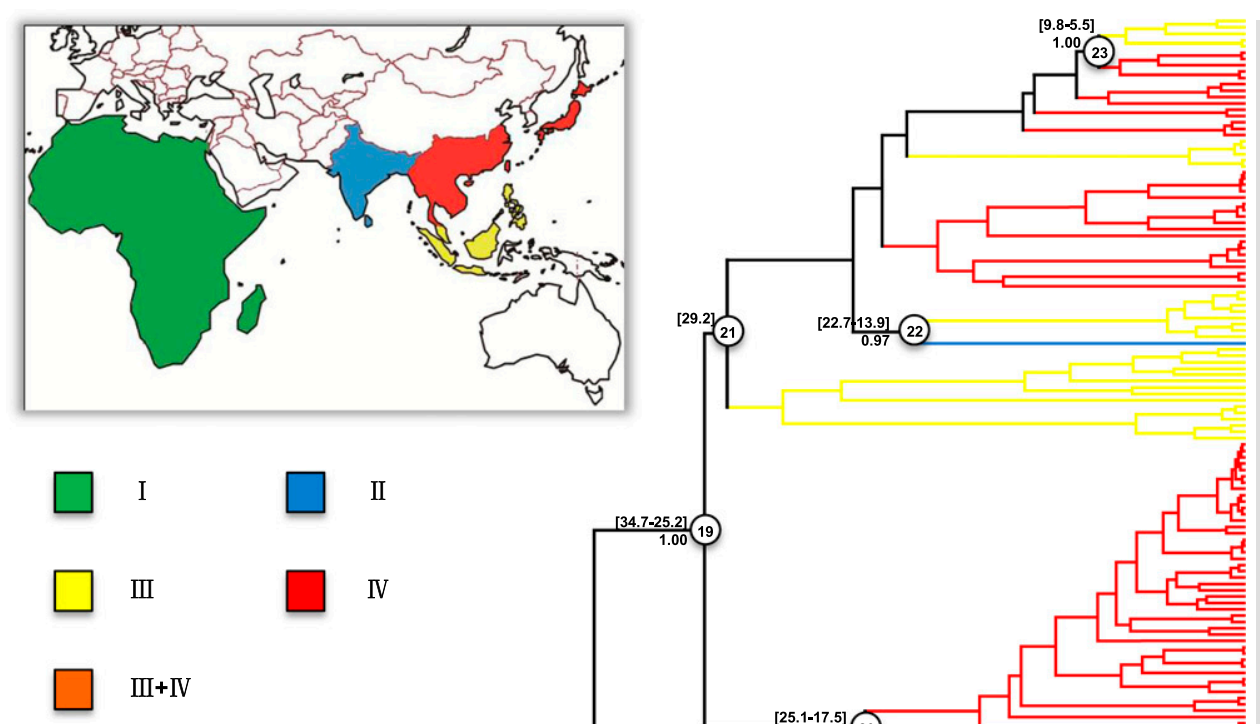

II

IV

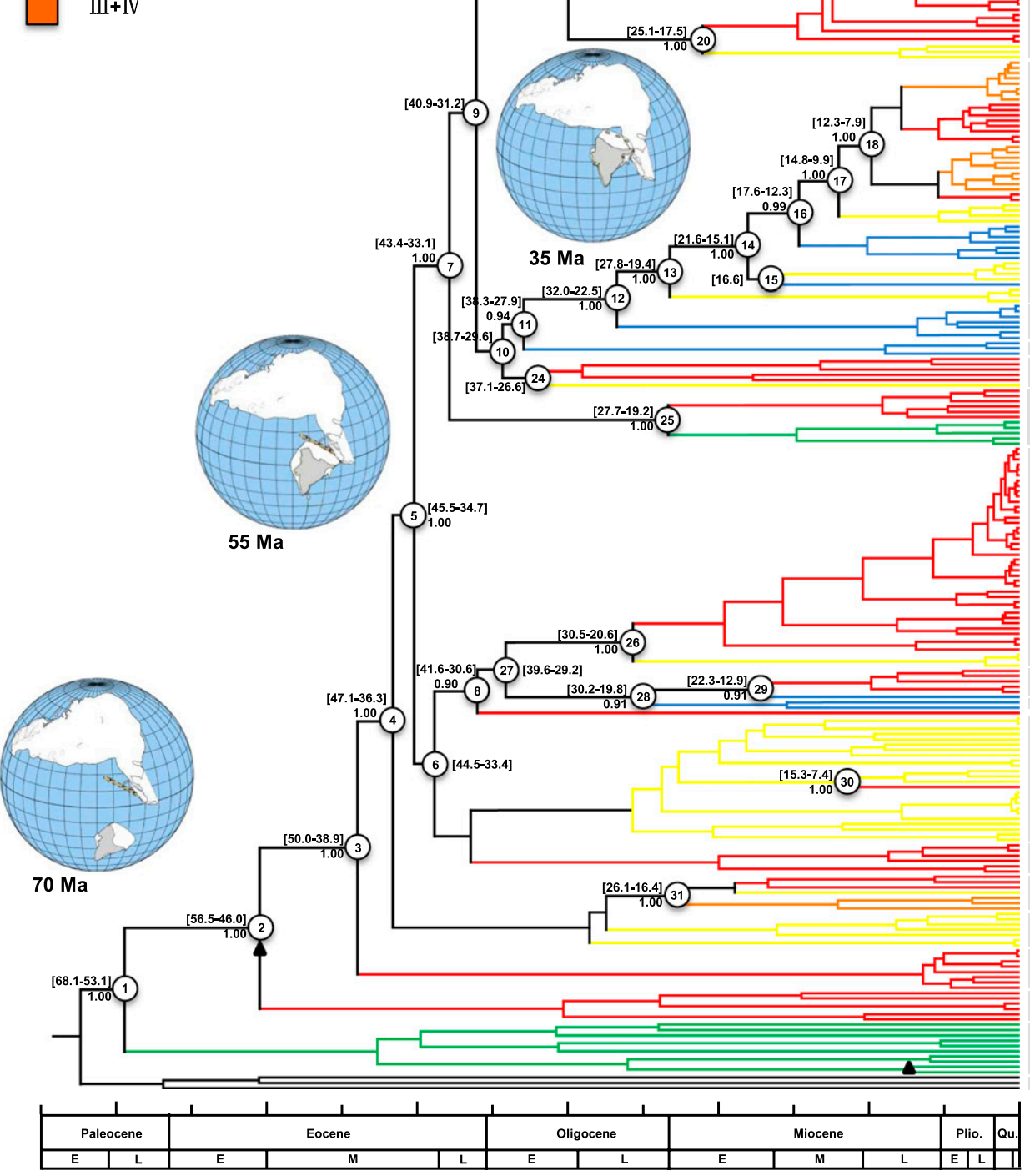

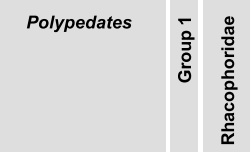

Fig. 1. Bayesian phylogenetic tree of the combined nuclear and mitochondrial dataset with posterior probabilities for branches ( $\geq 90 \%$ retained) and $95 \%$ credibility intervals for divergence time estimates. The area coding is illustrated in the Inset.

for the rhacophorid ancestors, as the MRCA of Rhacophoridae and Mantellidae is estimated at 53-68 Ma, and thus after the tectonic split of India and Madagascar $(30,31)$.
The oldest phylogenetic splits within the Rhacophoridae occurred in Asia, with all known extant Indian rhacophorids originating from later dispersal events to India (Figs. 1 and 2). Thus, 


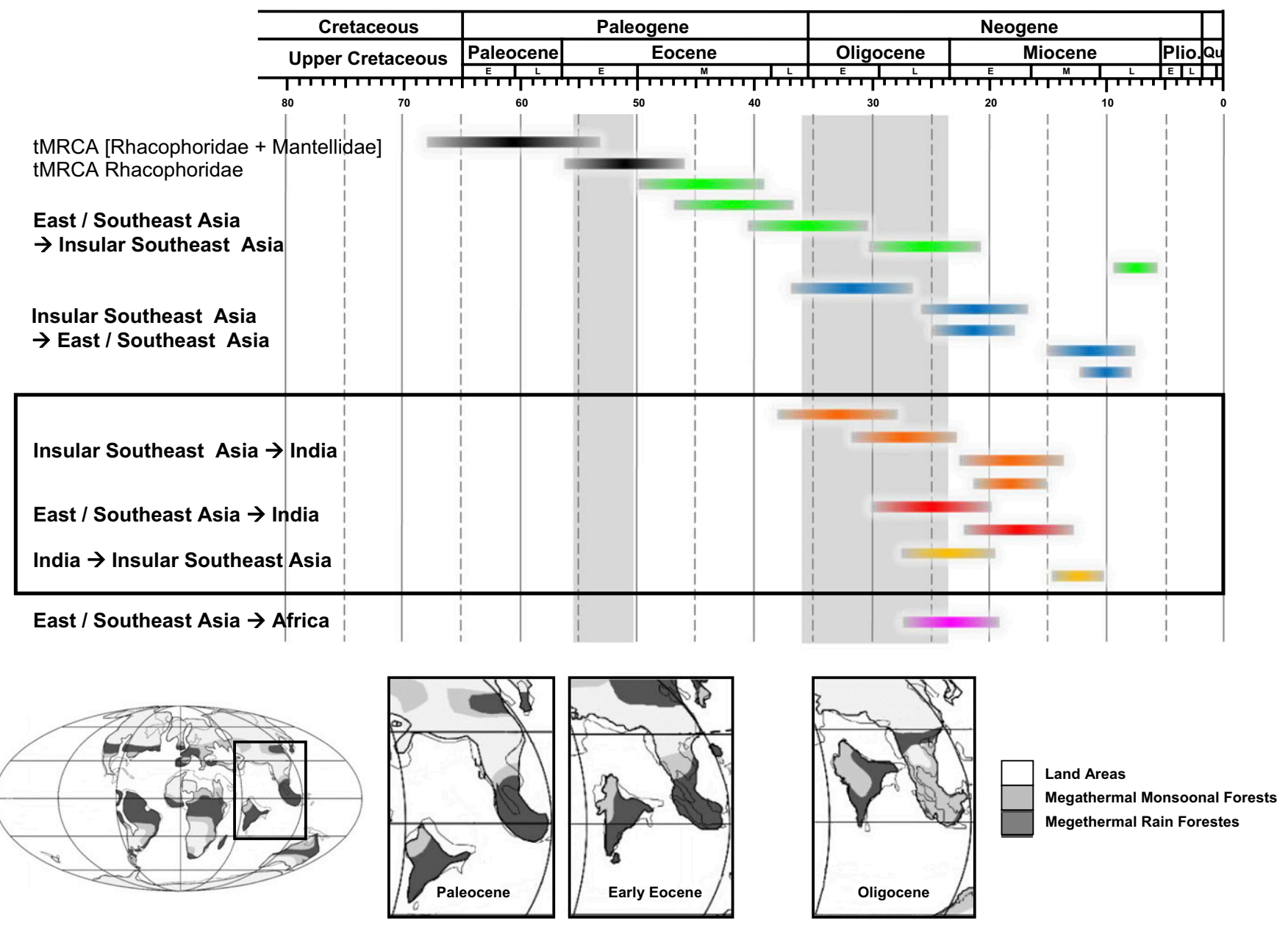

Fig. 2. Credibility intervals for the age of the most recent common ancestor of [Rhacophoridae + Mantellidae] and of the Rhacophoridae, and for dispersal events between areas. Paleoreconstructions and paleoclimate are modified from Aitchison et al. (10) and Morley (41).

extant rhacophorids clearly have an Asian origin. Nevertheless, the occurrence of Eocene fossil Rhacophoridae on the Indian subcontinent (33), which we have used to calibrate the MRCA of the family, argues for an Indian origin of Rhacophoridae, followed by dispersal to Asia that must have occurred before 46 and $57 \mathrm{Ma}$ (Fig. 1). Previous studies indicated that the Indian subcontinent experienced dramatic latitudinal and climatic changes that caused massive extinctions in its biota in the early Cenozoic $(1,34)$, and this might have also affected the rhacophorids.

How Rhacophorids Reached Asia Before the Final Collision Between India and Asia. Long-distance dispersal over the Tethys Ocean has to be considered unlikely for rhacophorid frogs, given their sensitivity to salinity and their arboreal habitat. Thus, a plausible geological model of the Indian-Asian collision should be able to explain $(i)$ the early dispersal of rhacophorids from India to Asia between 46 and 57 Ma (Fig. 1); (ii) the cessation of faunal exchange during the Middle Eocene (39-46 Ma); and (iii) the increase of rhacophorid dispersal events between the Indian subcontinent and Asia starting in the Late Eocene and continuing until the Middle Miocene (Figs. 1 and 2). Although the collision between India and Asia is currently the largest active orogeny (10), there exists much uncertainty regarding the position of India on its move northwards relative to the adjacent continents and the timing of the initial collision $(19,35)$, which are both highly controversial $(11,14-17)$.
Multiple studies have suggested that the Indian-Asian collision occurred during the Paleocene/Early Eocene at 50-55 Ma $(36,37)$. Most previous biogeographic studies rely on this date $(38,39)$. Also the estimated time frame when the rhacophorid ancestor dispersed from India to Asia fits into this scenario. However, recent geological models draw a more complex picture of the Indian-Asian collision $(10,16)$, proposing that the final collision that led to the uplift of the Himalaya was preceded around $50 \mathrm{Ma}$ by the collision of the Indian subcontinent with an intraoceanic island arc (10), followed by the continuing northward drift of the Indian subcontinent along Southeast Asia that might have allowed terrestrial connections (40). Alternatively, the Early Eocene collision event was caused by the accretion of a Tibetan-Himalayan microcontinent at 49-55 Ma that broke off the Indian subcontinent before (16). Both models are therefore able to explain an Early Eocene faunal exchange, followed by another period of continental isolation. The existence of a microcontinent that acted as a "ferry" for the rhacophorid ancestor that is dated between 46 and 57 Ma (Fig. 1) is compelling. As megathermal rainforests were widespread across India and Asia at the Paleocene-Eocene boundary (41) (Fig. 2), rhacophorids are likely to have expanded their range onto the Asian mainland very quickly. This could explain why the clades that diverged earliest within Rhacophoridae (Buergeria and Liuixalus) currently only occur in East Asia, far from the Indian subcontinent. 
No Faunal Exchange Between Southeast Asia and India During the Middle Eocene. During the Eocene (52-34 Ma) rhacophorids dispersed between East/Southeast Asia and Insular Southeast Asia (Fig. 2), as evidenced by the presence of the genera Nyctixalus and Theloderma in Southeast Asia (areas III and IV, Fig. 1). There was, however, no exchange of species between Asia and India. The most straightforward interpretation is that there were no terrestrial connections with India at that time. The "traditional" geological view on the Indian-Asian collision (assuming a final contact of plates during the early Eocene) thus fails to explain why dispersal between India and Asia ceased during the following 10 million years, although climatic conditions supposedly would have been favorable for tropical tree frogs during this period (41). The more recent geological models that argue for a later final collision seem to fit the present biogeographic data better. Van Hinsbergen et al. (14-17) suggested that there was no continent-continent contact from $52 \mathrm{Ma}$ (the accretion of the Tibetan-Himalayan microcontinent) to 25-20 Ma (the final collision of the Indian subcontinent). In contrast, Aitchison and Ali (10-13) inferred that the final continent-continent collision began around the Eocene/Oligocene boundary (34 Ma).

Faunal Exchange Between Asia and India Since the Oligocene. According to the rhacophorid data, frequent faunal exchange between Southeast Asia and the Indian subcontinent started during the Early Oligocene (Fig. 2 and Table S2, node 10). This is consistent with the model of Ali and Aitchison (10) for the timing of the final continental collision. In contrast, a final collision at 25-20 Ma (16) appears to be much later than our time estimates of Neogene rhacophorid dispersal from Asia to India.

Faunal exchange between the Indian subcontinent and Asia ceased again at the transition between Middle and Late Miocene around $12 \mathrm{Ma}$. We propose that this correlates with the rapid uplift of the Himalayan mountains that continued until $10 \mathrm{Ma}$ (42), leading to the establishment of the Indian and East Asian monsoon (43), and thus of more seasonal climates. Whereas in northern India extant rhacophorids are absent due to the monsoonal climate, the humid and warm conditions of East and Southeast Asia from the Miocene onwards (41) likely resulted in the rapid diversification of Rhacophoridae (e.g., the genera Rhacophorus, Polypedates, and Kurixalus).

The biotic interchange between the Indian subcontinent and Asia significantly contributed to the vast biodiversity of present-day East and Southeast Asia. This is consistent with inferences from mammalian fossils and paleobotanical data (44-46). We predict that the Oligocene faunal exchange between the Indian subcontinent and Asia, as shown here for rhacophorid frogs, also applies for other terrestrial nonvolant organisms with an IndianAsian distribution $(8,19)$, and suggest that previous studies that deal with this faunal interchange should be carefully reinvestigated.

\section{Materials and Methods}

Taxon Sampling and Data Collection. Our sampling covered the entire distribution of Rhacophoridae from tropical Africa and Asia to temperate China and Japan (Table S1). Whenever possible, samples from the type localities of nominal taxa were included and multiple samples were used to represent widespread species. Currently, 15 genera with 321 species of rhacophorids are recognized $(25,47)$. The mitochondrial DNA (mtDNA) dataset included 317 samples from all 15 rhacophorid genera, representing 114 species. For the analyses of the nuclear DNA (nDNA) markers, at least three species were sampled from each genus, totaling 64 taxa. We used two species of the family Dicroglossidae, 1 from the Ranidae, and 10 from the Mantellidae as outgroup taxa. Both the nDNA dataset and the combined mtDNA and nDNA data were used to perform phylogenetic analyses, molecular dating, and biogeographic reconstruction.

DNA Extraction, Amplification, and Sequencing. Genomic DNA was extracted from toe clips, muscle, or liver tissue preserved in $95 \%$ or $100 \%$ ethanol.
Tissue samples were digested using proteinase $\mathrm{K}$ and then followed a standard three-step phenol/chloroform extraction procedure $(48,49)$.

The mtDNA sequences comprised partial 12S and 16S rRNA together with the complete tRNA for valine using primers from previous studies (50-52). PCR was conducted as described previously $(50,51)$. Forward and reverse strands of purified PCR products were sequenced with an ABI 3730 automated DNA sequencer controlled via BLAST searching (53) against GenBank to ensure that the target sequences had been amplified. The nDNA data originate from a previous study (51) and include five gene fragments: BDNF, POMC, RAG-1, RHOD, and TYR. GenBank accession numbers for both the new and previously deposited data are given in Table S1.

Phylogenetic and Divergence Time Analyses. Sequences were aligned using ClustalX 1.81 (54) with default parameters, and subsequently minor adjustments were made to improve alignments following visual inspection. Positions that could not be confidently aligned were excluded to remove potentially misleading data. Gaps resulting from the alignment were treated as missing data. Because all mtDNA gene sequences are effectively inherited as one locus, they were concatenated into a single contiguous alignment for the analyses. For the mtDNA and each nDNA gene, possible saturation of substitution types was checked by plotting the number of transitions and transversions versus F84 distance using DAMBE (55).

We simultaneously inferred phylogeny and divergence time estimates using a Bayesian relaxed molecular clock approach on the combined mtDNA and nDNA datasets using BEAST 1.6.3 (56). We incorporated partitioned strategies (57) and treated each gene as one part separately. After a preliminary series of test runs, we chose the following models to fit best to the data: the uncorrelated lognormal relaxed molecular clock model, a Yule tree prior, and $\mathrm{GTR}+\mathrm{I}+\Gamma$ for the substitution model for each gene dataset. We performed a total of eight BEAST runs. The Markov chain Monte Carlo (MCMC) was run for 30 million generations and sampled every 1,000 generations. Convergence of MCMC chains was checked in Tracer 1.4.1 (58) and subsequently verified using the cumulative and compare functions in AWTY (59).

We calibrated the age of the most recent common ancestor of the Rhacophoridae with the age of fossil Indorana prasadi from Early Eocene sediments of India (33). The prior distribution for a fossil-based age constraint was modeled with a $\Gamma$-distribution (shape value $=4$; scale factor $=2$ ) with the fossil's minimum age ( $45 \mathrm{Ma}$ ) as younger cutoff value. We also applied the split between Boophis tephraeomystax, an inhabitant of the Comoro island of Mayotte, and its sister species (Boophis doulioti) $(30,60)$ as an age constraint for the second calibrated time. Mayotte is a volcanic, oceanic island with no known previous connections to a larger landmass; thus the $B$. tephraeomystax lineage could not have split from its sister lineage before $15 \mathrm{Ma}$, the maximum age of the island $(30,60)$. Therefore, we modeled the calibration age constraint using a broad uniform prior distribution from $15 \mathrm{Ma}$ to present. We show the nuclear Bayesian and combined mitochondrial and nuclear data trees using the fossil and biogeographic calibrations (combined mitochondrial and nuclear data, Fig. 1; nuclear phylogeny Fig. S2).

Area Delimitation and Biogeographical Reconstruction. We compiled distribution data of rhacophorid species from the literature (25) and assigned the included taxa to the respective ranges. To answer our initial hypothesis, i.e., the direction of faunal exchange between the Indian subcontinent and Eurasia, we divided the rhacophorid range into four areas (Fig. 1): Africa (area I); the Indian subcontinent (area II); Insular Southeast Asia including the Malay Peninsula (area III); and East/Southeast Asia (area IV). Each species was assigned to its associated area according to its contemporary distribution range. Widespread species were assigned to more than one area (Table S1).

Biogeographical inferences were obtained by applying statistical dispersal-vicariance analysis (S-DIVA) and Bayesian binary MCMC (BBM) analysis implemented in RASP v2.0 using the default settings (61). Random 1,000 BEAST output trees were used and the maximum number of individual unit areas was set to two. In addition to these event-based biogeographic methods, we also applied a parametric approach based on dispersal, extinction, and cladogenesis as implemented in the software Lagrange v. 20120508 (62). The analysis used the maximum clade credibility tree of the Bayesian phylogenetic analysis and the same area coding as for the event-based methods. The maximum size of ancestral ranges was set to two; adjacency of areas was not constrained. To test if the faunal exchange between the Indian subcontinent and Eurasia fits better to an earlier final collision of the two landmasses around $35 \mathrm{Ma}$ (10) or rather a later one around $25 \mathrm{Ma}$ (16), we compared different temporal dispersal models: an unconstrained model, a model that only allows faunal exchange after $35 \mathrm{Ma}$ and one allowing dispersal only after $25 \mathrm{Ma}$. Based on the global likelihood of the models we ranked them according to their Akaike Information Criterion values and Akaike weights (Table S3). 
ACKNOWLEDGMENTS. We thank M. Brandley, R. Murphy, and L. Zhang for valuable suggestions; K. He, Y. Zheng, and X. Guo for discussion; reviewers J. Aitchison and T. Near for constructive comments; and the following people and institutions for the loan of critical material: A. Resetar (The Field Museum of Natural History) and J. V. Vindum (California Academy of Sciences). R. MacCulloch and A. Lathrop assisted

1. Karanth KP (2006) Out-of-India Gondwanan origin of some tropical Asian biota. Curr Sci 90:789-792.

2. Biju SD, Bossuyt F (2003) New frog family from India reveals an ancient biogeographical link with the Seychelles. Nature 425(6959):711-714.

3. Bossuyt F, Milinkovitch MC (2001) Amphibians as indicators of early tertiary "out-ofIndia" dispersal of vertebrates. Science 292(5514):93-95.

4. Conti E, Eriksson T, Schönenberger J, Sytsma KJ, Baum DA (2002) Early Tertiary out-of India dispersal of Crypteroniaceae: Evidence from phylogeny and molecular dating. Evolution 56(10):1931-1942.

5. Datta-Roy A, Karanth KP (2009) The out-of-India hypothesis: What do molecules suggest? J Biosci 34(5):687-697.

6. Gower DJ, et al. (2002) A molecular phylogeny of ichthyophiid caecilians (Amphibia: Gymnophiona: Ichthyophiidae): out of India or out of South East Asia? Proc Biol Sci 269(1500):1563-1569.

7. Roelants K, Jiang J, Bossuyt F (2004) Endemic ranid (Amphibia: Anura) genera in southern mountain ranges of the Indian subcontinent represent ancient frog lineages: Evidence from molecular data. Mol Phylogenet Evol 31(2):730-740.

8. Wilkinson M, A Sheps J, Oommen OV, Cohen BL (2002) Phylogenetic relationships of Indian caecilians (Amphibia: Gymnophiona) inferred from mitochondrial rRNA gene sequences. Mol Phylogenet Evol 23(3):401-407.

9. Marshall LG (1988) Land mammals and the Great American Interchange. Am Sci 76: 380-388.

10. Aitchison JC, Ali JR, Davis AM (2007) When and where did India and Asia collide? J Geophys Res 112:B05423.

11. Aitchison JC, Ali JR (2012) India-Asia collision timing. Proc Natl Acad Sci USA 109(40): E2645-, author reply E2646.

12. Ali JR, Aitchison JC (2008) Gondwana to Asia: Plate tectonics, paleogeography and the biological connectivity of the Indian sub-continent from the Middle Jurassic through latest Eocene (166-35 Ma). Earth Sci Rev 88:145-166.

13. Ali JR, Aitchison JC (2012) Comment on "Restoration of Cenozoic deformation in Asia and the size of Greater India" by D. J. J. van Hinsbergen et al. Tectonics 31:TC4006.

14. van Hinsbergen DJ, et al. (2011) Restoration of Cenozoic deformation in Asia and the size of Greater India. Tectonics 30:TC5003.

15. van Hinsbergen DJ, et al. (2012) Reply to comment by Ali and Aitchison on "Restoration of Cenozoic deformation in Asia, and the size of Greater India" Tectonics 31 TC4007.

16. van Hinsbergen DJ, et al. (2012) Greater India Basin hypothesis and a two-stage Cenozoic collision between India and Asia. Proc Natl Acad Sci USA 109(20):7659-7664.

17. van Hinsbergen DJ, et al. (2012) Reply to Aitchison and Ali: Reconciling Himalayan ophiolite and Asian magmatic arc records with a two-stage India-Asia collision model. Proc Natl Acad Sci USA 109:E2646.

18. Beck RA, et al. (1995) Stratigraphic evidence for an early collision between northwest India and Asia. Nature 373:55-58.

19. Klaus S, Schubart CD, Streit B, Pfenninger M (2010) When Indian crabs were not yet Asian-biogeographic evidence for Eocene proximity of India and Southeast Asia. BMC Evol Biol 10:287.

20. Che J, et al. (2010) Spiny frogs (Paini) illuminate the history of the Himalayan region and Southeast Asia. Proc Natl Acad Sci USA 107(31):13765-13770.

21. Duellman WE, Trueb L (1986) Biology of Amphibians (McGraw-Hill, New York).

22. Heinicke MP, Duellman WE, Hedges SB (2007) Major Caribbean and Central American frog faunas originated by ancient oceanic dispersal. Proc Natl Acad Sci USA 104(24): 10092-10097.

23. Zeisset I, Beebee TJC (2008) Amphibian phylogeography: A model for understanding historical aspects of species distributions. Heredity (Edinb) 101(2):109-119.

24. Zhang P, et al. (2006) Phylogeny, evolution, and biogeography of Asiatic Salamanders (Hynobiidae). Proc Natl Acad Sci USA 103(19):7360-7365.

25. Amphibian Species of the World. Version 5.5. Electronic Database. (American Museum of Natural History, New York). Available at http://research.amnh.org/vz/ herpetology/amphibia/. Accessed January 31, 2011

26. Frost DR, et al. (2006) The amphibian tree of life. Bull Am Mus Nat Hist 297:1-370.

27. Pyron RA, Wiens JJ (2011) A large-scale phylogeny of Amphibia including over 2800 species, and a revised classification of extant frogs, salamanders, and caecilians. Mol Phylogenet Evol 61(2):543-583.

28. Liem SS (1970) The morphology, systematics, and evolution of the Old World tree frogs (Rhacophoridae and Hyperoliidae). Fieldiana: Zool 57:1-145.

29. Richards CM, Moore WS (1998) A molecular phylogenetic study of the Old World tree frog family Rhacophoridae. Herpetol J 8:41-46.

30. Bossuyt F, Brown RM, Hillis DM, Cannatella DC, Milinkovitch MC (2006) Phylogeny and biogeography of a cosmopolitan frog radiation: Late cretaceous diversification resulted in continent-scale endemism in the family ranidae. Syst Biol 55(4):579-594.

31. Van Bocxlaer I, Roelants K, Biju SD, Nagaraju J, Bossuyt F (2006) Late Cretaceous vicariance in Gondwanan amphibians. PLOS ONE 1:e74. with collection work at the Royal Ontario Museum. This work was supported by grants from the National Basic Research Program of China (a 973 Program grant), the National Natural Science Foundation of China (31101618 and 31071894), a China Postdoctoral Science Foundation Funded Project (20100471689), and the US National Science Foundation (EF-0334952).

32. Vences M, Kosuch J, Glaw F, Böhme W, Veith M (2003) Molecular phylogeny of hyperoliid treefrogs: Biogeographic origin of Malagasy and Seychellean taxa and re analysis of familial pa-raphyly. J Zoological Syst Evol Res 41:205-215.

33. Folie A, et al. (2012) Early Eocene frogs from Vastan Lignite Mine, Gujarat, India. Acta Palaeontol Pol, 10.4202/app.2011.0063.

34. Rutschmann F, Eriksson T, Schönenberger J, Conti E (2004) Did Crypteroniaceae really disperse out-of-India? Molecular dating evidence from rbcL, ndhF, and rpl16 intron sequences. Int J Plant Sci 165:69-83.

35. Ali JR, Aitchison JC (2006) Positioning Palaeogene Eurasia problem: Solution for $60-50$ $\mathrm{Ma}$ and broader tectonic implications. Earth Planet Sci Lett 251:148-155.

36. Patriat P, Achache J (1984) India-Eurasia collision chronology has implcations for crustal shortening and driving mechanisms of plates. Nature 311:615-621.

37. Leech ML, Singh S, Jain AK, Klemperer SL, Manickavasagam RM (2005) The onset of India-Asia continental collision: Early, steep subduction required by the timing of UHP metamorphism in the western Himalaya. Earth Planet Sci Lett 234:83-97.

38. Clyde WC, Khan IH, Gingerich PD (2003) Stratigraphic response and mammalian dispersal during initial India-Asia collision: Evidence from the Ghazji Formation, Balochistan, Pakistan. Geology 31:1097-1100.

39. Sahni A (2006) Biotic response to the India-Asia collision: Changing palaeoenvironments and vertebrate faunal relationships. Palaeont Abt A Palaozool-Stratigr 278:15-26.

40. Acton GD (1999) Apparent polar wander of India since the Cretaceous with implications for regional tectonics and true polar wander. Mem Geol Soc India 44 129-175.

41. Morley RJ (2011) Tropical Rainforest Responses to Climate Change, eds Bush MB Flenley JR (Springer, Heidelberg), pp 1-34

42. Royden LH, Burchfiel BC, van der Hilst RD (2008) The geological evolution of the Tibetan Plateau. Science 321(5892):1054-1058.

43. Liu XD, Yin ZY (2002) Sensitivity of East Asian monsoon climate to the uplift of the Tibetan Plateau. Palaeogeogr Palaeoclimatol Palaeoecol 183:223-245.

44. Guo ZT, et al. (2002) Onset of Asian desertification by $22 \mathrm{Myr}$ ago inferred from loess deposits in China. Nature 416(6877):159-163.

45. Qiu ZD, Li C (2004) The evolution of mammal fauna in China and the uplift of Qinghai-Xizang Plateau. Sci China Ser D 34:845-854.

46. Sun $X$, Wang $P$ (2005) How old is the Asian monsoon system? Palaeobotanical records from China. Palaeogeogr Palaeoclimatol Palaeoecol 222:181-222.

47. Meegaskumbura M, et al. (2010) Taruga (Anura: Rhacophoridae), a new genus of foam-nesting tree frogs endemic to Sri Lanka. Ceylon J Sci. Biol Sci 39(2):75-94.

48. Hillis DM, Moritz C, Mable BK (1996) Molecular Systematics (Sinauer, Sunderland, MA), 2nd Ed.

49. Sambrook J, Fritsch EF, Mantiatis T (1989) Molecular Cloning: A Laboratory Manual (Cold Spring Harbor Lab Press, NY), 2nd Ed.

50. Li JT, Che J, Bain RH, Zhao EM, Zhang YP (2008) Molecular phylogeny of Rhacophoridae (Anura): A framework of taxonomic reassignment of species within the genera Aquixalus, Chiromantis, Rhacophorus, and Philautus. Mol Phylogenet Evol 48(1):302-312

51. Li JT, et al. (2009) New insights to the molecular phylogenetics and generic assessment in the Rhacophoridae (Amphibia: Anura) based on five nuclear and three mitochondrial genes, with comments on the evolution of reproduction. Mol Phylogenet Evol 53(2):509-522.

52. Wilkinson JA, Drewes RC, Tatum OL (2002) A molecular phylogenetic analysis of the family Rhacophoridae with an emphasis on the Asian and African genera. Mol Phylogenet Evol 24(2):265-273.

53. Altschul SF, et al. (1997) Gapped BLAST and PSI-BLAST: A new generation of protein database search programs. Nucleic Acids Res 25(17):3389-3402.

54. Thompson JD, Gibson TJ, Plewniak F, Jeanmougin F, Higgins DG (1997) The CLUS $T A L \_X$ windows interface: Flexible strategies for multiple sequence alignment aided by quality analysis tools. Nucleic Acids Res 25(24):4876-4882.

55. Xia X (2000) DAMBE: Data Analysis in Molecular Biology and Evolution (Kluwer Academic, Boston)

56. Drummond AJ, Rambaut A (2007) BEAST: Bayesian evolutionary analysis by sampling trees. BMC Evol Biol 7:214

57. Brandley MC, Schmitz A, Reeder TW (2005) Partitioned Bayesian analyses, partition choice, and the phylogenetic relationships of scincid lizards. Syst Biol 54(3):373-390

58. Rambaut A, Drummond AJ (2007) Tracer v1.4. Available at http://beast.bio.ed.ac.uk/ Tracer. Accessed June 15, 2009.

59. Nylander JAA, Wilgenbusch JC, Warren DL, Swofford DL (2008) AWTY (are we there yet?): A system for graphical exploration of MCMC convergence in Bayesian phylogenetics. Bioinformatics 24(4):581-583.

60. Vences M, et al. (2003) Multiple overseas dispersal in amphibians. Proc Biol SCi 270(1532):2435-2442.

61. Yu Y, Harris AJ, He XJ (2011) RASP (Reconstruct Ancestral State in Phylogenies) 2.0 beta. Available at http://mnh.scu.edu.cn/soft/blog/RASP. Accessed July 15, 2012

62. Ree RH, Smith SA (2008) Maximum likelihood inference of geographic range evolution by dispersal, local extinction, and cladogenesis. Syst Bio/ 57(1):4-14. 